deprived of proteids in the imago stage it lays no egys. Of the anatomical condition of the reproductive organs in the flies experimentally reared no evidence is vouchsafed.

Plymouth, September I5. J. T. CunNivgham.

"Darwinism is not Evolution."

I wAS very much struck-having heard the admirable reply which Prof. IYuxley gave to Lord Salisbury on the evening of August $3-$ to find a passage in "Darwin's Life and Letters" (vol. iii. p. 13) which is the exact counterpart of the chief point in Huxley's retort. Darwin writes to Lyell (March 12, 1863): "I must feel convinced that at times . . . you have as completely given up belief in immutability of specific forms as $I$ have done. . . The more I work the more-satisfied I become with variation and natural selection, but that part of the case I look at as less important, though more interesting to me personally."

It was whispered in Oxford that Huxley had spoken of Darwinism rather lightly in comparison with evolution. The above-quoted passage shows that even in this respect Darwin himself had set the example.

I have reason to believe that these illustrious examples will not be very generally followed. A. A. W. H.

Utrecht, September II

\section{Extraordinary Phenomenon.}

HAVING recently had before me your number of the 6 th inst.' I feel very desirous to bring under your notice, for insertion in your journal, the description of a most extraordinary and singular phenomenon as was observed by me at Llanberis, $\mathrm{N}$. Wales, on Sunday, August 26 last, about 10.30 p.m. especially as I perceive that the time of my observation coincides precisely with the time recorded in that number by John IV. Earle, at Gloucester, describing his observation of a remarkable meteor which he discovered.

I was outside the hotel in Llanberis at $10.3^{\circ} \mathrm{p} . \mathrm{m}$. admiring the lustre of the stars-for it was a cloudless night-when, gazing upwards into the region of Cassiopeia, I was startled by a sudden flash from a brilliant effulgence of white light situated proximately to the two stars of greatest magnitude in that constellation, which immediately resolved itself into a clearly defined disc, about three times the diameter of Jupiter. After a brief interval I observed a body of brilliant orange colour dis charged from the disc, which was projected directly towards Perseus. This body assumed a form resembling an elongated flatfish, but terminating in a point, the disc forming a nucleus to the apparition, which was marvellous to behold; but its visibility proved to be only of short duration, for the white disc, or nucleus, suddenly disappeared, leaving the orangecoloured mass quiescent for about half a minute, and then I saw it fade away gradually, and it vanished out of my sight.

The appearance of this strange body did not occupy more than five minutes of time; its dimensions in length I estimated was about fifteen degrees of arc. I likewise noticed an important fact-that it evidenced no motion in space.

During my professional career, including Arctic and Equatorial services, a great part was spent in nightly watchings, in which all sorts of meteoric phenomena came under my notice, jet I never beheld one which manifested such marked singularity and distinctiveness combined. I could only regret that no one was at hand to affirm what I saw.

With reference to the meteor observed by John IV. Earle in Ursa Major, I wish to mention that a building excluded that constellation from my sight, therefore it establishes a very interesting and important fact that these two extraordinary phenomena, one in Ursa Major, the other in Cassiopeia, were so distinctly notified by two observers so remote from each other at the very same moment.

Erasuus Omananey, Admiral.

29 Connaught Square, IV., September 24.

\section{"Aurelia aurita."}

AT the Plymouth Laboratory, in July last, I examine ${ }_{3} \mathrm{~S}_{3}$ adult specimens of Aurelia attrita, and found eight specimens ( $2 \circ \mathrm{O}$ per cent.) showing a numerical variation in the generative sacs and buccal arms.

One specimen with 3 generative sacs, 3 buccal arms, and 9 tentaculocysts. Three specimens with 3 generative sacs, NO. I 300 , VOL. 50]
3 buccal arms, and each one has traces of a fourth generative sac and a fourth arm. Two have 8 tentaculocysts, and one has ro tentaculocysts. One specimen with 5 generative sacs, 5 buccal arms, and $S$ tentaculocysts. Three specimens with 6 generative sacs, 6 buccal arms; two have It tentaculocysts, and one has 12 tentaculocysts. Six specimens with the normal number of buccal arms and genera. tive sacs show a variation in the size and shape of the sacs. There appears to exist a correlation between the generative sacs and buccal arms, but the tentaculocysts vary independently of the other organs.

I found 87 specimens $(22.8$ percent.) showing a variation in the number of tentaculocysts. Twenty specimens possess less than the normal number, and the remainder show an excess. The range of variation extends from 6 to 15 tentaculocysts.

University College, London, September I5.

\section{Science in the Medical Schools.}

IN the issue of NATURE of September 20, I notice a table of the scientific classes which are to be given in the medical schools of Great Britain during the session 1894-95; In this table I find that the subject of "biology or zoology" is indicated by a cross $(x)$ as being taught in all the medical schools of Scotland with the exception of the University of Aberdeen. You will, doubtless, allow me to point out that in this matter Aberdeen is in precisely the same position as Edinburgh and Glasgow. A course of zoology is delivered in the University of Aberdeen in the winter session, and a second course in the summer session, and there is, in addition, a course of practical zoology.

University, Aberdeen.

H. Alleye Nicholsos.

ON THE DOCTRINE OF DISCONTINUITY OF FLUID MOTION, IN CONNECTION IVITH THE RESISTANCE AGAINST A SOLID MOVING THROUGH A FLUID.

$\S \mathrm{I}$. THE doctrine that "discontinuity," that is to say" finite difference of velocity on two sides of a surface in a fluid, would be produced if an inviscid incompressible fluid were caused to flow past a sharp edge of a rigid solid witli no vacant space between fluid and solid was, I believe, first given by Stokes in I $\$ 47 .^{1}$

It is inconsistent with the now well-known dynamical theorem that an incompressible inviscid fluid initially at rest, and set in motion by pressure applied to its boundary, acquires the unique distribution of motion throughout its mass, of which the kinetic energy is less than that of any other motion of the fluid with the same motion of its boundary.

$\S 2$. The reason assigned for the formation of a surface of finite slip between fluid and fluid was the infinitely great velocity of the fluid at the edge, and the corresponding negative-infinite pressure, implied by the unique solution, unless the fluid is allowed to separate itself from contact with the solid. This an inviscid incompressible fluid certainly would do, unless the pressure of the fluid were infinitely great everywhere except at the edge. In nature the tendency to very great negative pressure arising from greatness of velocity of a fluid flowing round a corner is always obviated by each one of three defalcations from our ideal :-

(I.) Viscosity of the fluid, preventing the exceeding greatness of the velocity.

(II.) Compressibility of the fluid.

(III.) Yielding-ness of the outer boundary of the fluid.

$\$$ 3. Defalcation (I.) is in many practical cases largely operative when air is the fluid ; but (II.) is also largely operative in some very interesting cases, such as the withistling of a strong wind blowing round a sharp corner or through a chink; the blowing against the sharp edge in the embouchure of an organ-pipe, and in the mouth1 "Collected Papers," vol.i. pp. 3ro, 3tr. 
piece of a flageolet or of a small "whistle"; and the blowing across the end of a tube or a hole in the side of a tube, to cause a key or a flute to sound.

$\S 4$. Defalcation (III.) is largely operative, and (II.) but little, in many practical cases of most common occurrence in the flow of water. It is probable that much of the foam seen near the sides and in the wake of a screw steamer going at a high speed through glassy: calm water, is due to "vacuum" behind edges and roughnesses causing dissolved air to be extracted from the water. A stiff circular disc of ro-inch diameter, and $\mathrm{r} / \mathrm{s} 0$ of an inch thick in its middle, shaped truly to the figure of an oblate ellipsoid of revolution would cause a vacuum ${ }^{1}$ to be formed all round its edge, if moved at even so small a velocity as I foot per second under water of any depth less than 63 feet; if water were inviscid : and at greater depths the motion would, on the same supposition, be wholly continuous, with no vacuum, and would be exactly in accordance with the unique minimum energy solution.?

While the velocity of the fluid across the equator is 63.7 feet per second, the velocity across each of the two parallel circles whose radii are 4.218 inches (the radius of the equator being 5 inches) is only 1 foot per second.

$\$ 5$. The exceedingly rapid change of shape of the fluid flowing across the equatorial zone between these circles, with velocity at the surface augmenting from I foot per second to 63 feet per second in advancing over a distance of less than 85 of an inch of the surface from one of the small circles to the equator, and diminishing again from 63 to I from the equator to the other parallel, in a small fraction of a second of time would, if the fluid is water or any other real liquid, give rise, through vis. cosity, to forces greatly diminishing the maximum velocity, and causing, through fluid pressure, the motion of the water to differ greatly from that of the minimum-energy solution, not only near the equator, or in its wake, or over the rear side of the disk; but over all the front side also, though no doubt much more on the rear side and in the wake, than on the front side, and in the fluid before it.

The viscosity would also, at less depths than 63 feet, have great effect in keeping down the maximum velocity; and it is possible that even at 1o or 20 feet a greater velocity than I foot per second might be required to make vacuum round the equator of our disc of 10 inches diameter and the $\bar{z} \overline{0} \overline{0}$ of an inch radius of curvature which its elliptic meridianal section gives it. But it seems quite certain that there must be much forming of vacuum, and consequent extraction of air and rising of bubbles, to the surface, from the somewhat sharp corners, and roughnesses, of iron, in the hull of an ordinary iron sailing ship or steamer, going through the water at twelve knots (that is, $20 \mathrm{ft}$. per second). KELVIN.

\section{(To be continued.)}

[Correction on previous short article, "Towards the Efficiency of Sails, Sc." In last line but two, for $2 \pi$ substitute $3 \pi$. In last line but one, delete 4 , and for $S$ substitute 32.]

1 Single word to denote space vacated by water.

a From the elementary hydrokinetics of the motion of an ellipscid through an inviscid incompressible fuid, originated by Green, who first gave the solu. tion for the case of translational motion of the ellipsoid, we know that, if $\theta$ denoting the angle between the axis of an oblate ellipsoid of revolution, of which the equarorial and polar areas are $a, b$, the velocity of the fluid flowing over this point of the surface is

$$
\frac{\left(a^{2}-b^{2}\right) \mathrm{V} \sin \theta}{b\left\{b+\frac{a^{2}}{\sqrt{\left(a^{2}-b^{2}\right)}} \sin -11^{\prime} \frac{\left(a^{2}-b^{2}\right)}{a}\right\}}
$$

if the velccity of the fluid at $\mathrm{rreat}$ distances from the solid is $\mathrm{V}$, and in parallel lines, and the solid is held fixed in the fuid, with its axis parallel to these lines. Taking $a=100 b$ in this formula, $\alpha=$ reduce it $10 \stackrel{200}{ } \mathrm{~V} \sin \theta$ approximately within s per cent.; and taking $\sin \theta=1$, and $V^{\pi}=1$ foot per second, we find $6: 7$ feet per secord for the velccity acress the equator. Hence the gravitaional head corresponding to the "rezative-pressure" is $\left(63^{*} 7^{2}-1^{2}\right)^{\prime} 64^{*} 4$, cr very approximately 63 leet, which froves the statement in the text.

$$
\text { No. I } 3 \mathrm{CO} \text {, voL. } 50 \text { ] }
$$

\section{SCIENCE, IN SCHOOL AND AFTER SCHOOL.}

$\mathrm{T} T$ is an unfortunate accident of the conditions under which instruction in science has grown up, that in speaking of science teaching two essentially dissimilar things should be confused. This confusion has very seriously affected-and still affects-the development of method in this country. It arises from the fact that, twenty or thirty years ago at least, the ordinary schoolmaster was quite without the knowledge necessary to teacli science, and that even when his scientific knowledge was a measurable quantity, that ignorance of psychology which was and which remains one of his most constant characteristics, rendered him incapable of innovations upon the tradition of mental training he cherished. Consequently what knowledge people obtained of the growing body of science came after the elementary stage of education was over, when their minds and senses had already received a considerable amount of cultivation and were, for good or evil, definitely developed in a prescribed way. The teaching given, therefore, did not aspire to be so much educational as instructive; it made the best of a bad job, and without any belated attempts to alter the fundamental intellectual mechanism, placed therein so much of the new facts and views as the circumstances permitted. It was addressed primarily to adolescence and to the adult, its methods were by lecture, diagram and text-book, and the written examination or a practical examination, turning chiefly on the identification of specimens or the interpretation of diagrams, was the adequate measure of its value. Such teaching can affect the taught only through their opinions and knowledge; it can discover scientific capacity, but it can neither develop nor very largely increase it, because it comes too late in the mental life. It is typically represented by the innumerable classes over which the Science and Art Department presides.

On the other hand, we have the science teaching that is educational, that takes the pupil still undeveloped and trains hand, eye, and mind together, enlarges the scope of the observation, and stimulates the development of the reasoning power. Such science teaching occurs at present most abundantly in theoretical pedagogics. It is, however, undoubtedly the proper science teaching for the school, if science is to have a place in the school. For it is universally conceded nowadays that the school is a training place, that there the vessel is moulded rather than filled, and that the only justification for the introduction of science is its educational value. Equally indubitable is it that it should be confined to school limits. An attempt to make the adult science teaching educational in the same sense, would be-to complete the image-extremely like putting a well-baked-if imperfect-vessel back upon the potter's wheel.

Now, hitherto the chief influence of this confusion has been to hamper truly educational science teaching in schools. Those who had as adults studied science under the Science and Art Department, or in University lecture theatres, took their text-books and the methods under which they had acquired their knowledge into the school, where the conditions were altogether different. The course of science lessons began as a lecture in which the class listened to colourable imitations at second or third hand of this or that eminent exponent of scientific theory. The more discerning teachers after a time realised the futility of requiring genuine lecture notes from such immature minds, and supplied the deficiency by dictating a colourable imitation. They also provided copies on the blackboard for such original sketches as were required, and indeed went to very considerable pains to keep the outward appearance of the lecture system intact. Examiners of schools-being selected without the slightest reference to their capacity to examine-fell very readily into this view, that school science-teaching was adult 